\title{
Teaching Engineering Design and Communication in First Year Using Rube Goldberg Projects
}

\author{
David deMontigny, Heidi Smithson, Connor Wright \\ University of Regina, Faculty of Engineering and Applied Science \\ david.demontigny@uregina.ca
}

\begin{abstract}
First year engineering classes tend to be very large and impersonal, which can make it difficult for instructors to engage the students. Since the first year of courses is critical in setting students up for success in engineering, being able to inspire them and give them some hands on experience during their introduction to engineering design plays a significant role in bolstering their confidence and interest as they enter more demanding and technical upper-level courses. With an aim toward achieving this inspiration and engagement, the first year engineering design and communication class at the University of Regina included the production of Rube Goldberg machines as the term project. This proved to be a very effective mechanism for teaching students how to work on a design project from start to finish. The students had fun and stretched their imaginations. As a result, the overall feedback from students was very positive, but areas for improvement have been identified.
\end{abstract}

\section{Introduction}

Over the past several years, first year students in the Engineering Communications and Design (ENGG 113) class at the University of Regina have been put into groups to complete a design project. Projects were generally successful, but they tended to be conceptual, predictable, and sometimes a tad boring. The end result was that ENGG 113 was just another class, and the vast majority of students were not inspired by the experience. In an effort to change the situation, the design project was redeveloped with a focus on creativity, fun, and hands-on learning. The introduction of Rube Goldberg machines into the course dramatically improved student response in the class. This paper will discuss the management of the course and how Rube Goldberg machines can be used to improve the learning experience for students in first year engineering design courses.

\subsection{Rube Goldberg Machines}

In short, a Rube Goldberg machine is a complex device that accomplishes one or more simple tasks in a controlled, convoluted, and sometimes humourous manner [1]. The machines themselves are highly over-engineered, prone to failure, and have limited application, if any. On the positive side, they serve as an excellent vehicle for learning. Arguably, one of the most famous Rube Goldberg machines ever built was the one shown in the 2003 Honda Accord commercial, which featured a long chain reaction of interacting parts from a disassembled Accord leading to a display of an intact vehicle [2].

\section{The Projects}

The class was divided into 27 groups of six, and each group was required to design, build, and demonstrate the successful operation of a Rube Goldberg machine. Rather than give each group the same project, five differently-themed projects were randomly assigned to the groups. This allowed for some variety in the class, as it may have been repetitive and boring to see the same project done 27 different times. Table 1 outlines the five different projects that were used this year. Note that each project had a primary task, a starting action, and six sub-goals that needed to be completed in order for the Rube Goldberg machine to be considered completely functional.

In addition to building a working Rube Goldberg machine, each group was also required to complete the following tasks at the end of the semester:

- Submit a technical report that detailed the design of their machine.

- Deliver a 15 minute project presentation.

- Demonstrate their project to the rest of the class, either with a live demonstration or by showing a video of their machine in action. 
Table 1. ENGG 113 Rube Goldberg Projects (2009)

\begin{tabular}{|c|c|}
\hline Theme 1 & Monty Python and the Holy Grail \\
\hline Primary Task & Launch a 'flying' rabbit a distance of 2 meters. \\
\hline Start Action & A boulder is released and begins rolling (boulder is initially stationary). \\
\hline Sub-Goals & $\begin{array}{l}\text { - Bowl over monks; a minimum of } 3 \text { monks must topple. } \\
\text { - Raise the castle flag a minimum distance of } 10 \mathrm{~cm} \text {. } \\
\text { - Raise and lower the of a dragon. } \\
\text { - Crack an egg on the head of Sir Robin. } \\
\text { - Launch arrows at a minstrel. }\end{array}$ \\
\hline Theme 2 & Spies and Espionage (i.e.: James Bond, Get Smart) \\
\hline Primary Task & Launch a boat over a dock $10 \mathrm{~cm}$ over water. \\
\hline Start Action & An alarm clock activates (use voltage, vibration, etc.). \\
\hline Sub-Goals & $\begin{array}{l}\text { - Raise a Canadian flag to the tallest point on the machine. } \\
\text { - Turn on emergency lights (minimum of three lights). } \\
\text { - Shred a secret document ( } 8.5 \text { x 11) into } 3 \text { pieces. } \\
\text { - Have Bond dive into water. } \\
\text { - Shake, not stir, a 'martini'; vibrations must be well-evidenced. } \\
\text { - Decapitate a statue with a bowler hat. }\end{array}$ \\
\hline Theme 3 & Space (i.e.: Star Trek) \\
\hline Primary Task & Abduct 5 cows in a container at least $30 \mathrm{~cm}$ above the cows. \\
\hline Start Action & A ball is dropped onto a target (ball may be held by group member). \\
\hline Sub-Goals & $\begin{array}{l}\text { - Fill a Cardassian pint glass. } \\
\text { - Pombard a Borg Cube (a minimum of } 3 \text { times from a distance of } 0.5 \mathrm{~m}) \text {. } \\
\text { - Trap a commander in a Jell-O mould of death. } \\
\text { - Topple } 5 \text { Klingon invaders placed at separate locations. } \\
\text { - Transport a load of Latinum to within } 30 \mathrm{~cm} \text { of the highest point on the machine. }\end{array}$ \\
\hline Theme 4 & Canadian Winter \\
\hline Primary Task & Wrap tape around a hockey stick (need at least 2 revolutions of tape). \\
\hline Start Action & A pulley weight is released (must activate a pulley system). \\
\hline Sub-Goals & $\begin{array}{l}\text { - Raise a Canadian flag (must be the tallest point on the machine). } \\
\text { - Slide } 5 \text { tobagganers/skiers down a hill into a bucket of water. } \\
\text { - Put a toque on a snowman. } \\
\text { - Have a beaver chop down a tree. } \\
\text { - Throw snowballs at a snow fort (hit the target } 3 \text { times from a distance of } 0.5 \mathrm{~m} \text { ). }\end{array}$ \\
\hline Theme 5 & Jurassic Park \\
\hline Primary Task & Execute an escape sequence with a Jurassic Park jeep that ends when a helicopter lifts the jeep. \\
\hline Start Action & The escaping jeep must be used to initiate the system in any manner. \\
\hline Sub-Goals & $\begin{array}{l}\text { - Have a Tyrannosaurus eat a lawyer off a toilet. } \\
\text { - A Dilophosaurus spits in Nedry's face. } \\
\text { - Raunch Timmy from the electric fence. } \\
\text { - Catch } 3 \text { raptor eggs in a backpack. } \\
\text { - Restore the island's power (must turn on at least } 3 \text { lights around the 'island'). }\end{array}$ \\
\hline
\end{tabular}




\subsection{Project Constraints}

In order to help guide the students, some constraints were put on the project. They were also used to help level the playing field for all of the groups. While the constraints may have limited some creativity, they did give everyone a framework to work under.

- The use of chemicals, gases, weapons, etc., was only allowed with permission from the instructor.

- Materials and actions that create a hazardous environment, such as releasing noxious fumes, were not permitted.

- The machine's dimensions could not exceed 2.25 $\mathrm{m}$ long by $1.0 \mathrm{~m}$ wide by $2.5 \mathrm{~m}$ tall.

- The total weight of the machine was not allowed to exceed 85 kilograms.

- The project had to be free standing on a table.

- Project materials were to cost less than $\$ 100$.

- The run time of the machine was supposed to be between two to four minutes, with a three minute target.

- All goals were to be completed in a distinct and sequential fashion. While parallel routes were allowed, each goal had to be accomplished in a discrete step and time; multiple goals could not be executed simultaneously.

- The Primary Task had to be completed last.

The constraints were useful as two groups requested to use a paint gun in their project and safety concerns had to be addressed. The restriction on dimensions led many groups to build their machine on a piece of plywood that had been cut to an appropriate size.

\subsection{1 "Patents"}

To inject a bit of fun competition into the design project, groups were allowed to 'patent' a technology that they developed. This would limit other groups from using the same technology in their project. Alternatively, groups could licence their patent to other groups if a licensing agreement could be negotiated. Any patents that were awarded to a group were only applicable to similarly-themed Rube Goldberg projects. Patents were submitted to and approved by the instructor.

Over the course of the semester, two groups applied for a patent. One was approved, and the other was rejected because it lacked innovation. The patent that was approved was valid for the Monty Python theme. The group had designed an air cannon to launch their rabbit by pressurizing a $2.0 \mathrm{~L}$ plastic pop bottle. The rabbit was launched when one of actions in the machine opened a valve attached to the pop bottle, releasing air into a 'cannon' made of PVC tubing.

\section{Evaluation}

The Rube Goldberg project accounted for $40 \%$ of the final grade in the course. The distribution of the marks is shown in Table 2. Note that equal weight was given to the project design (working machine) and the formal report that detailed the whole group project. ENGG 113 is engineering communications and design, and an emphasis is placed on the communication side of engineering. Unfortunately, many engineering students struggle with writing, especially in their first few years at university. By getting them to practice writing formal reports, they gain experience as writers and receive an introduction to one of the most fundamental forms of engineering communication - reports.

Table 2. Allotment of Marks

\begin{tabular}{|l|l|}
\hline Project Design (50\%) & \multicolumn{1}{|c|}{ Project Report (50\%) } \\
\hline Functionality (35\%) & Technical (20\%) \\
Complexity (10\%) & Design Description (25\%) \\
Creativity (5\%) & References (5\%) \\
\hline
\end{tabular}

The project design was graded based on a number of criteria including successful completion of tasks, clarity of design, and ease of fabrication. Extra credit was given when motion in the machine was achieved in a controlled fashion. Other factors such as the ease of resetting the machine, reliability of a successful run, and the incorporation of the project theme were also considered. Students were required to submit a video showing at least one successful continuous (un-edited) operational run of their machine, which was used to assign the design grades.

The project report was judged on whether it clearly communicated the design concept and methodology that was used. Students were to explain the processes using technical language. The report was also expected to contain diagrams, an analysis of their project (with an emphasis on how each subtask and constraint was met), a list of their materials and expenses, and a conclusion with an emphasis on what was learned (what worked and did not work and what recommendations would they make to other groups and future Rube Goldberg designers?).

\subsection{Project Presentations}

Groups were required to deliver a fifteen minute presentation in front of the class to present their Rube Goldberg project. In this presentation, they were to explain and defend their design choices, discuss the selection of materials, outline their expenses, and show their machines in action. Some groups chose to 
bring their machine to class and give a live demonstration, but the majority of teams played a video of their machine in action. At the end of the presentation, groups had to answer questions from their classmates. This became especially interesting, as groups that were working on projects of the same theme tended to be critical of each others' design choices. To ensure reasonable attendance of all presentations, it was emphasized that questions on specific presentation details would appear on the final exam for the course.

\section{Results and Discussion}

The expectation at the start of the semester was that students would build relatively simple machines that met the requirements of the project. To our great surprise and delight, the students built complex machines that were clever, amusing, and inspired. Some of the notable methods used in the projects included:

- chemical solutions to complete an electric circuit

- using motors and timing devices

- developing and running a computer program to open the DVD drive as a physical component of the sequence

- construction of complicated K'Nex structures

- using gravity, pulleys, and counterweights

- using compressed air, mouse traps, and catapults to launch objects

- using fire, razor blades and string as a means of controlling the timing and release of specific actions

The project itself really was a mini-engineering project that required (1) designing of the machine, (2) selecting materials, (3) following a budget, (4) assembly, testing and troubleshooting, and (5) reporting. When it came time to showcase their work, a number of groups went the extra mile and got uniforms/costumes for their presentations to play along with the theme of their project. Video editing was also part of the creativity shown, as many groups produced well-edited and highly dramatic productions to showcase their machines with added inventiveness.

Some teams imposed additional constraints. Most groups elected to use old toys and household items to meet budget constraints, but several groups selected recyclable materials to take into consideration the environmental impact and eventual disposal of their machines. One group was determined to build the simplest possible machine that still met all constraints, and another aimed to build the least expensive machine by restricting all components to items available at a "nothing over a dollar" type of store. Several groups considered aesthetics and exerted considerable artistic effort to make their machines visually appealing and reflective of the project theme.

\subsection{Student Feedback}

Feedback from the class was positive, as students felt that they were able to work on a team project from start to finish with tangible results. While there were some personality conflicts in some of the groups, most teams worked well to achieve their goal.

The majority of students enjoyed the Rube Goldberg project, but they did say it was a lot of work. There were a handful of students that did not like the project at all. Predictably, they did not give reasons why, but group dynamics may have left some people with a bad experience. The most common suggestion from students regarding the project was to add more time in the lab portion of the class so that groups could get together to work on their project. This is a reasonable request, as it became apparent that some of the groups had difficulty finding a suitable time and location to meet outside of class. This was especially problematic for international students living on campus, as many groups met and worked in local homes. Since many of the project-building sessions were conducted late at night, outside of bus service hours, it was hard for some international students to join their groups. Interestingly, one group budgeted travel expenses for one of their group members as part of their spending strategy.

\subsection{Changes for Next Year}

Some major changes were identified for future Rube Goldberg assignments. The first relates to the specified run-time for the machines. Groups were asked to build a machine that ran for two to four minutes, with a run-time of three minutes being ideal. To achieve this, groups employed time wasting devices such as water dripping from a cup, salt pouring through a funnel, or string being wrapped around the shaft of a motor. This made watching the various machines boring at times. Therefore the required run time will be reduced and limitations will be placed on the use of time wasting steps. Some constraints might be set on how long each task must take to ensure better balance between steps in the machine.

The second major change required relates to group participation. Group members were allowed to rank the level of participation of each member, and grades were distributed to the group members based on their 
level of participation. In other words, group members who failed to complete tasks or attend meetings were entitled to only a portion of the project mark based on their group's evaluation of their performance. There were some problems with this system, and it will need to be modified. Some students were too passive to assert a place in their group or to approach the instructors for assistance if they were being left out. In the future, more emphasis will be placed on guiding group formation to ensure that all members understand their responsibilities and to encourage the more passive students to be more proactive about establishing a place for themselves within their group. Students will be regularly directed to seek guidance if major issues are occurring within their group.

Another smaller change that is needed relates to the project budget. Several groups spent more than the $\$ 100$ that was suggested. Nobody complained about the expense of their machine. In fact, many of the students were quite happy to invest in their design to make it better. However, the point of the assignment was to design a functional machine while being resourceful. More emphasis will be put on the economics in the future. Groups that went over budget were required to justify overspending in their final report.

\section{Conclusions}

Group design projects are regularly required in the ENGG 113 design class. In past years, design projects have been conceptual with limited opportunity for students to engage in hands-on project design. This past year Rube Goldberg machines were used in the class for the first time with the aim of increasing student interest in the course and providing a more tangible introduction to engineering design and project management by giving the students an opportunity to engage in a hands-on design and construction task. Overall, the quality of the design projects and the participation of the students was improved from previous years. For a first time effort, the implementation of Rube Goldberg machines as a course project was a considerable success. As a result, the concept will be adopted into the regular curriculum of the course. The goal will be to develop an engaging first year engineering design class that leaves students excited and inspired about their chosen profession.

\section{References}

[1] Google Videos. Retrieved July 14, 2009, from Rube Goldberg Commercial Web site: http://video.google.com/videoplay?docid=4187430023476942057

[2] Kennedy, L. Rube Goldberg Homepage. Retrieved July 14, 2009, Web site: http:Iwww.rubegoldberg.com 